ENTREPRENEURSHIP AND SUSTAINABILITY ISSUES

ISSN 2345-0282 (online) http://jssidoi.org/jesi/

2020 Volume 7 Number 3 (March)

http://doi.org/10.9770/jesi.2020.7.3(56)

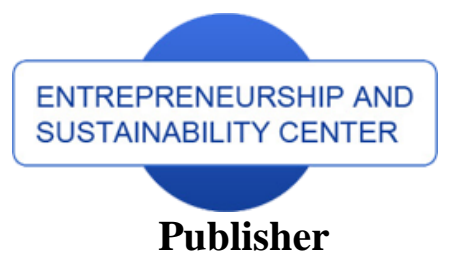

http://jssidoi.org/esc/home
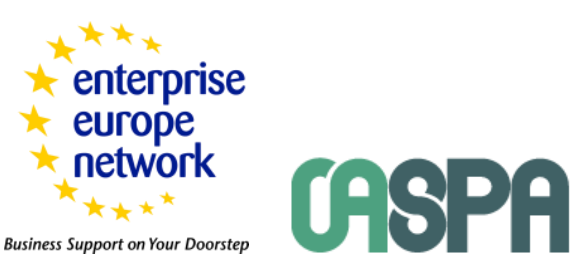

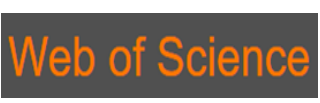

I Clarivate

Analytics

\title{
KNOWLEDGE AUDIT AS A KEY TOOL FOR BUSINESS RESEARCH IN THE INFORMATION SOCIETY
}

\author{
Liudmila V. Kashirskaya ${ }^{* 1}$, Alexey A. Sitnov ${ }^{2}$, Dilmurod Ash. Davlatzoda ${ }^{3}$, Tatiana M. Vorozheykina ${ }^{4}$ \\ ${ }^{1}$ Financial University under the Government of the Russian Federation, Leningradsky Prospekt, 49, 125993, Moscow, \\ Russian Federation \\ ${ }^{2}$ Financial University under the Government of the Russian Federation, Leningradsky Prospekt, 49, 125993, Moscow, \\ Russian Federation \\ ${ }^{3}$ Tajik National University 35, Ayni Ave 734025, Dushanbe, Republic of Tajikistan \\ ${ }^{4}$ Russian State Agrarian University - Moscow Agricultural Academy named after K.A. Timiryazev, 127550 \\ Timiryazevskaya st., 49, Moscow, Russian Federation \\ E-mails:*2kashirskaya76@mail.ru
}

Received 14 August 2019; accepted 10 December 2019; published 30 March 2020

\begin{abstract}
The article discusses and systematizes the possibilities of knowledge audit in the frames of the formation of the information society. The features of developing a methodology, organization and knowledge audit tools that meet the modern needs of the development of business audit are assessed. The problem of modern times also lies in the fact that the audit of explicit (formalized) knowledge is fundamentally different from the audit of implicit (non-formalized) knowledge. As one of the main areas of business audit, knowledge audit is highly professional consulting services in a wide range of subject areas of economic, financial, legal and many other areas of modern business. A research of the demand for this area of audit in the global community showed that the lack of an agreed methodology prevents from making the decision about conducting an audit of knowledge. The article examines modern approaches that allow combining the capabilities of modern business audit in general and information systems audit, operational audit, intellectual capital audit and knowledge audit, in particular. It is concluded that combining these types of audits into a single audit of a business shows a significant business effect. The practical significance of the article lies in the fact that conclusions and suggestions aimed at strengthening the role of modern audit contribute to the real optimization of modern business. A research made by the authors showed that the new reality of the 21 st century has changed the attitude towards traditional audit, which requires justification of the business effect when introducing new information systems and modernizing old ones, moving from complex automation of business processes to specialized solutions. Notwithstanding with it, the demand for business development and IT strategies and feasibility studies is growing steadily. Projects on the use of corporate knowledge at all levels of management come to the fore.
\end{abstract}

Keywords: knowledge audit; corporate memory; knowledge management system; explicit (formalized) knowledge; implicit (nonformalized) knowledge; reengineering; optimization; intellectual capital; intellectual potential; intangible assets; knowledge assets

Reference to this paper should be made as follows: Kashirskaya, L.V., Sitnov, A.A., Davlatzoda, D.A., Vorozheykina, T.M. (2020). Knowledge audit as a key tool for business research in the information society. Entrepreneurship and Sustainability Issues, 7(3), 22992312. http://doi.org/10.9770/jesi.2020.7.3(56)

JEL Classifications: M 41, M 42, M 49, G22. 


\section{ENTREPRENEURSHIP AND SUSTAINABILITY ISSUES}

ISSN 2345-0282 (online) http://jssidoi.org/jesi/

2020 Volume 7 Number 3 (March)

http://doi.org/10.9770/jesi.2020.7.3(56)

\section{Introduction}

In the frames of modern global changes, accompanied by continuous technological changes, which are being carried out at a very rapid pace, a need of quick search for appropriate and relevant information on an unprecedented scale arises almost simultaneously with the appearance of this information in the information space surrounding these systems. The business seeks to improve and strengthen its capabilities by strengthening the emphasis on a modern and progressive management methodology, the so-called knowledge management methodology.

At the same time, knowledge in this context is understood as a combination of data and information, including various combinations of new technologies, production experience, emotions, culture, values of indicators, ideas, intuition, motivation, styles of learning, attitudes, ability to trust and solve complex problem situations, frankness, the ability to work in a modern information network, sociability, attitude to permanent risk, the presence of an entrepreneurial spirit (Kashirskaya et al., 2019; Saenko et al., 2019; Voronkova et al., 2019).

In the general understanding, knowledge management is a set of conceptual apparatus, subject disciplines and tools for organizing knowledge that allow managers to take responsibility for corporate knowledge and, based on this corporate knowledge, effective management decisions.

The tendency of managers to use knowledge leads to the accumulation of particularly valuable assets, improves their ability to make and use in practice effective rather than traditionally rational management decisions.

According to J. Gardner, one of the famous modern researchers of management problems, the only possible stability of the existence of business is "the stability in motion". And since the movement is generated by contradictions, their resolution consists in the search for "dynamic balance" between the stability of the business system and its continuous improvement, that is, in the search for new effective management decisions, as outdated stereotypes become unacceptable for this subject (Gardner, 1981).

The concept of "management decision" is usually considered from three points of view. Firstly, it denotes a process of a certain sequence of management actions aimed at choosing the optimal path for the activity of this subject. Secondly, it is the process of choosing an option to solve a particular problem or task. A problem is a complex theoretical or practical aspect that requires study and resolution. Usually "a problem means a mismatch between the desired (normative) and actual levels of achieving goals" (Golubkov, 2005, p. 45). And, finally, thirdly, it is a specific managerial action (Trofimova et al., 2019; Luzina et al., 2019; Suryono et al., 2019; Prodanova et al., 2019).

Any control process is a definite and continuous in time sequence of actions, combined into appropriate stages according to the quality content and uniformity of those operations that are necessary for their implementation. The making of managerial decisions, as mentioned earlier, is preceded by a study of the current situation and the choice of options for these decisions related to a particular problem. Therefore, a situation is understood as "a combination of conditions and circumstances in which a problem arose" (Golubkov, 2005, p. 45). Ideally, it is desirable to have all possible options of action that could eliminate the causes of the problematic disturbances and, thus, provide the business with the opportunity to achieve the stated goals. Identification and description of a problem situation provides an initial information base for evaluating the time available for making a decision and the amount of resources needed for this. However, in practice, managers most often do not have sufficient relevant information and, moreover, time to identify and evaluate each alternative solution. At the same time, a significant number of alternative solutions are more likely to interfere than to help management. Therefore, as a rule, managers are limited to a small number of options for those decisions that correspond only to a certain 


\section{ENTREPRENEURSHIP AND SUSTAINABILITY ISSUES}

ISSN 2345-0282 (online) http://jssidoi.org/jesi/

2020 Volume 7 Number 3 (March)

http://doi.org/10.9770/jesi.2020.7.3(56)

minimum requirement established by the business itself. However, the best decision is considered to be the one that is most often called optimal in economic literature. At the same time, under conditions of constant uncertainty, it is not always possible to find the optimal and at the same time strictly formalized solution (Golubkov, 2005).

Famous scientists in the field of control theory M.K. Meskon, M. Albert and F. Hedouri believe that in the case when managers "... are not able to assess what will happen if nothing is done, there is a danger not to resist the demand for immediate action. Action for the sake of action increases the probability of responding to an external symptom of a problem, rather than its main cause" (Meskon, 2002, p. 205).

In his turn, G. Simon argues that, when solving a particular problem, business usually is incined to behavior that cannot be called as optimization of managerial decisions. In this case, the optimal management solution is not used at all because of the lack of time and the inability to take into account all relevant information and a significant number of possible options for such a solution. In this situation, managers may take inappropriate actions that are subjectively acceptable, but not always the best of all possible (Simon, 1995).

In practice, knowledge is divided into explicit (formalized), expressed in objects, words, numbers, graphic forms, drawings, specifications, textbooks, procedures, and implicit (unformalized), which are theoretical models, models of behavior and perspectives based on empirical data and experience of the carriers of this knowledge themselves (Kashirskaya et al., 2019, Lafer and Tarman, 2019; Nonaka and Takeuchi, 1995; Sharafutdinov et al., 2019; Neizvestnaya et al., 2018; Akhmetshin et al., 2018).

However, up to nowadays, all efforts aimed at creating modern systems of knowledge management in business are reduced, as a rule, only to the promotion of individual information technologies related to the introduction of modern software products that allow solving only certain aspects of this problem. In a number of cases, in the most developed business, these technologies are combined into a single information system for a business at various levels of its development (Korableva et al., 2018).

In the era of modern and very intense changes in the 21 st century, traditional approaches to management, which guarantee business success for a long time, cannot stop the gradual decline of its resistance to both internal contradictions and external threats from a very aggressive and sometimes very unpredictable competitive environment. A static, non-developing, corporate memory that serves as the basis for making managerial decisions becomes an increasingly distorted view of the future for business, and the rules and procedures established in business begin to lose their significance over time (Gibbert et al., 2002).

Corporate memory in this context is an implicit or explicit interpretation of business processes or manufactured products, goods or services that does not subject to business. It should be borne in mind that "companies, like people, remember the past, including old processes and procedures, as well as corporate traditions and values." (Koulopoulos and Frappaolo, 1999, p. 114).

Being in a similar situation, managers often initiate radical transformations based on reengineering, rebuilding their business and IT processes and, what is most important, business strategies under new business conditions, modern challenges, and threats, while destroying the established internal knowledge potential of their business systems. Thus, in the process of such business transformations, managers make a huge mistake, replacing the outdated (in their opinion) corporate memory with new knowledge at that moment and practically stop there. At the same time, there is a desire to withdraw the most experienced knowledge carriers from business and replace them with younger, but less competent employees. 


\section{ENTREPRENEURSHIP AND SUSTAINABILITY ISSUES}

ISSN 2345-0282 (online) http://jssidoi.org/jesi/

2020 Volume 7 Number 3 (March)

http://doi.org/10.9770/jesi.2020.7.3(56)

Researches of scientists and modern practice have proved that a fixed in time view of a problem situation is typical for reengineering. The reason for this lies in the inability to take into account the characteristic features of modern markets, continuously progressing, and very rapid changes occurring in a competitive environment (Koulopoulos and Frappaolo, 1999, p. 114).

Thus, the knowledge acquired by the business as a result of reengineering also very soon becomes obsolete. An urgent need for a repeated and at the same time very costly transformation of the business model arises. According to the opinion of the famous scientists and practitioners Thomas M. Culopoulos and Karl Frappaolo and with which one cannot disagree, the strength of modern business of the 21 st century is not in the knowledge that was used in the past and is outdated, “... but in the ability to constantly update the corporate wisdom repository and use its contents for new purposes" (Koulopoulos and Frappaolo, 1999, p. 12). However, an approach based on reengineering does not allow this process to be carried out continuously and requires more and more costs for new transformations (Nagimzhanova et al., 2019; Magsumov, 2017; Yemelyanov et al., 2018). Unlike reengineering, knowledge management defines a constant readiness of a business for managerial influences, contributes to continuous transformation and innovation at a speed that at least corresponds to the pace of the modern development of a competitive environment.

In modern conditions, changes are, of course, inevitable and continuous, therefore, innovative processes must be constant and continuous. The information base for this is precisely the repository of corporate wisdom. In order to remain successful and sustainable in today's constantly changing competitive environment, it is necessary to continuously accumulate knowledge and expand it in accordance with the needs of the future market, transforming corporate memory into corporate wisdom (Koulopoulos and Frappaolo, 1999, p. 116).

Thus, a new, intangible, form of resources appears in business - intellectual capital. At the same time, scientists and practitioners in the field of management have recently used the concept of "intellectual potential" of a business (Novgorodov, 2017; Nigamaev et al., 2018; Kopteva et al., 2019; Prakash and Garg, 2019).

Mentioned objects almost always existed in business, but they were identified relatively recently as a resource or an asset. Intellectual capital can be defined as the set of all the knowledge of employees of an individual business, ensuring its resistance to permanent challenges from the competitive environment (Makarov, 2005), or as the set of intangible assets of an individual business that can be used to create value for a consumer result (Nayanova, 2001).

In its turn, the "intellectual potential" is a stock of knowledge, abilities, skills, culture and morality, health, capable of capitalizing under certain conditions. Moreover, it does not have age limits and health restrictions (Kotyrlo, 2011).

The definition of knowledge as business assets and, accordingly, the existence of the need to manage this type of asset are discussed in the works of scientists-economists as well as management practitioners (Kashirskaya et al., 2019). Intellectual capital determines the competitiveness of the business in the information society and therefore becomes one of the key resources. In its turn, the intellectual potential is not a capitalized element of the development of society (Akhmadeev et al., 2019; Smolnikova et al., 2019).

The well-known scientist in the specified subject field Thomas Stewart defines the intellectual capital as all business knowledge that can be considered an asset and distinguishes three main elements in its structure human, structural and consumer capital. At the same time, human capital, in his opinion, represents the knowledge, skills and creative potential of business employees. In addition, here he also relates the culture of interpersonal relations. Structural (organizational) capital include patents, licenses, trademarks, brands belonging to a particular business, as well as hardware and software, organizational structure and methods of organizing 


\section{ENTREPRENEURSHIP AND SUSTAINABILITY ISSUES}

ISSN 2345-0282 (online) http://jssidoi.org/jesi/

2020 Volume 7 Number 3 (March)

http://doi.org/10.9770/jesi.2020.7.3(56)

business and IT processes. Consumer (client) capital is an information base about the clients of a particular business, including the evolution of relationships with them, as well as relationships (Stewart, 2001).

In his turn, Karl-Eric Sveiby proposed his approach to the consideration of the elements of intellectual capital. In his opinion, it is necessary to single out the competence of employees, internal and external structures (Sveiby, 2004).

Moreover, under the competence of employees, a scientist means their abilities, including their education, qualifications, experience, attitude to their functions and to the business in which they work. This element of intellectual capital depends on specific employees, and if they leave the business, the competence leaves with them. At the same time, the internal structure is nothing more than intangible assets belonging to a particular business, enabling it to satisfy customer preferences of customers. It relates to the internal structure business strategy, patents, know-how, information systems, information databases, organizational structure and documented business and IT processes.

And finally, the external structure, in his opinion, shows the relationship of among business and contractors. External structure includes brands, trademarks, image belonging to a particular business.

At the same time, it should be mentioned that these scientists do not quite unambiguously correlate the objects of intellectual capital to one or another of its elements. For example, Karl-Eric Sveiby defines the attitude to work to the competence of employees, but at the same time, attitude to work is also considered as part of the corporate culture of the business. Moreover, he relates the latter to the internal structure (Sveiby, 2004). Such approach inherently complicates the practical use of these theories for the formation and application of knowledge management systems. At the same time, these approaches to determining the elements of intellectual capital can be applied to assess its state in a particular business and can be used as a starting point in the development of a business strategy and management policy, as well as its development (Thalassinos, I.E. and Thalassinos, Y., 2018; Hilkevics and Semakina, 2019). By choosing one of the above as a working model, it is possible in the context of a single business to develop a classification of intellectual capital objects with a view to subsequently controlling them and developing ways to develop intellectual capital management on its basis.

In the economy of the 21 st century, the list of business systems whose success depends on the proper attitude to their knowledge is expanding rapidly. In large business, separate structural units are created and engaged in the development of a new consumer result (product, good or service), its introduction to the market, market research of its own consumer result, sale of high-tech products, and management of relations with contractors. The knowledge of the employees of these structural units of the business is of great importance for the entire business. The creating of modern effective knowledge management systems allows the specified business to solve the problems of distributing the knowledge system between the interested structural units of the business, as well as among its regionally separated employees who perform their functions in its geographical segments (Kotyrlo E. S., 2011).

In the context of the development of the information age, taking into account the needs of market participants, preventive consistent and at the same time independent control of the entire set of knowledge is necessary, focusing attention not only on the past, but also on the present and especially on the future of the controlled business, while erasing the boundaries between directly controlling functions and management consulting. 


\section{ENTREPRENEURSHIP AND SUSTAINABILITY ISSUES}

ISSN 2345-0282 (online) http://jssidoi.org/jesi/

2020 Volume 7 Number 3 (March)

http://doi.org/10.9770/jesi.2020.7.3(56)

\section{Methods}

In the opinion of well-known foreign scientists and practitioners, and with whom one cannot disagree, the most acceptable tool for highly professionally implementing these functions in their entirety is a modern audit, but not a traditional audit of financial statements, but an audit of the business as a whole. It is a business audit that should include, as a separate area of audit, a knowledge audit (Kashirskaya et al., 2019).

At the same time, in this context, an audit of knowledge should be understood as a systematic independent scientific audit of corporate knowledge, both past and present, and especially future (corporate memory and corporate wisdom) and the development of management recommendations for business management based on its results.

According to Anne Hilton, a knowledge audit specialist, only $15 \%$ of knowledge management developments are completed with appropriate results (Andrusenko, 2007). At the same time, the main reason for failures when introducing these systems into the business is the lack of a preliminary audit of corporate implicit (nonformalized) knowledge (Vyatkina and Sitnov, 2018; Korchevenkov and Aleksandrova, 2018).

In addition, the lack of a coherent methodology for auditing a business as a whole does not allow them to determine appropriate approaches to identifying implicit (unformalized) knowledge necessary for a particular business both in the current time and, which is especially important, in modern conditions of a rapidly changing competitive environment, and especially in a strategic perspective.

Thus, auditors are not able to prepare specific and appropriate management recommendations for the management of this knowledge for any modern business.

At the same time, it can be confidently sated that the audit of implicit (non-formalized) knowledge at the present stage of development of a business audit as a whole is a very complex and time-consuming scientific audit study, requiring high professionalism and competence from the auditors themselves. At the same time, it is necessary to understand that the goals in each specific audit assignment may be different, and their achievement in the audit study of implicit (non-formalized) business knowledge is ambiguous.

According to scientists and experts in the field of auditing, it is advisable to make an audit of this knowledge in the following cases:

- during developing a business strategy in the field of knowledge management;

- if there are significant difficulties in finding the necessary information or a competent specialist expert in a particular subject area;

- if there is duplication of the collection of information and implicit (non-formalized) knowledge;

- in case of doubt about the value of an initiative related to the use of an information system, investment in certain software products or business projects;

- during relatively low efficiency of implementation of the results of scientific research and experimental development $(\mathrm{R} \& \mathrm{D})$;

- during the reorganization of a business, its merger or acquisition (Kashirskaya et al., 2019).

In the course of the specified direction of the audit as part of a business audit, the auditor may:

- determine the organizational aspects and the readiness of the business for non-traditional transformations;

- develop management recommendations for the development of an adequate competitive environment requirements, a business strategy in the field of knowledge management, creation or development of the existing knowledge management system;

- identify hidden reserves of implicit (unformalized) knowledge for their further effective use by the management of the business under study; 


\section{ENTREPRENEURSHIP AND SUSTAINABILITY ISSUES}

ISSN 2345-0282 (online) http://jssidoi.org/jesi/

2020 Volume 7 Number 3 (March)

http://doi.org/10.9770/jesi.2020.7.3(56)

- determine the structure of the intellectual capital of the business and establish the most effective methods and procedures for its evaluation;

- identify and assess the likely loss of knowledge due to the departure of their carriers from the business;

- establish the potential for creating in business groups of the most competent practicing employees who create this or that knowledge;

- systematize the identified knowledge assets and develop for management an appropriate methodology for their assessment.

At the same time, it should be mentioned that conducting an audit of knowledge requires the implementation of a significant amount of work to create the proper conditions for the preparation of an information base. At the same time, the fundamental target setting is the formation among managers and knowledge carriers of the studied business of an appropriate understanding of its importance for increasing the effectiveness of the knowledge management system.

It should be borne in mind that an important component of the audit of implicit (non-formalized) knowledge, as noted earlier, is the individuality and atypicality of each business under study, its business strategies, as well as the need for direct close cooperation with its knowledge holders and the involvement of various subject matter experts areas.

Thus, at the planning stage, it is necessary first of all to assess the status of the existing business knowledge management system. For this purpose, according to a number of scientists and practitioners, as well as the studies conducted, we can consider that the most aprroriate is the use of the Capability Maturity Model proposed by the Software Engineering Institute by the US Department of Defense to classify and evaluate projects related to software development and quality assurance during the implementation of these projects (Sitnov and Urintsov, 2014; Ibbs and Kwak, 1997).

Assessment of implicit (non-formalized) knowledge by an auditor based on Maturity Models can serve as a qualitative component in the development of management recommendations for the practical implementation of the current and strategic management of the knowledge management system as a whole and its components in particular (Sitnov and Urintsov, 2014). Moreover, compliance with one or another level of the Model allows to determine the readiness of a business for modernization or updating. These Models allow the auditor to determine audit procedures that allow giving answers to what needs should be done during the audit on the essence of the audit engagement, as well as to establish the state in which the business knowledge management system is located.

In this study, the auditor must take into account that the first level of maturity corresponds to a situation when there are no formally accepted procedures for knowledge management in general in business and, as a result, which is especially important, implicit (unformalized) management plans, plans for its implementation are not created, work is poorly defined in content, volume and cost. Knowledge management processes are completely unpredictable and poorly controlled, and managers often do not understand key management issues. As a result, the success of the knowledge management system depends more on the individual efforts of knowledge holders than on the organization of management processes. A business at this level can be described as trying to spontaneously master the basic processes of knowledge management.

The second level of maturity (or as it is often called the "level of individual planning") corresponds to the use of separate informal and incomplete knowledge management procedures in an organization. Managers partially apply and control management processes. However, in each case, planning and management depends on the individual approach of a manager.

The third level of maturity (management level) involves a partial formalization of knowledge management processes and the use of a basic planning and management system in business. A business that has reached this 


\section{ENTREPRENEURSHIP AND SUSTAINABILITY ISSUES}

ISSN 2345-0282 (online) http://jssidoi.org/jesi/

2020 Volume 7 Number 3 (March)

http://doi.org/10.9770/jesi.2020.7.3(56)

level takes a systematic and structured approach to planning and control. The staff is trained to apply the methodology and tools of knowledge management.

The fourth maturity level (integration level) is characterized by full formalization with the official approval of all knowledge management processes and documentation (mapping) of relevant information. A business that has reached this level is able to effectively plan, manage and control the entire set of business processes they perform. Knowledge management processes are well defined, quantified, understood by staff and put into practice. Process related data is standardized, collected and stored in a database to ensure effective and objective analysis and quantification of processes, as well as to predict undesirable trends and prevent possible adverse situations. This allows the business to create the foundation for making effective management decisions.

And finally, at the highest, fifth level of maturity (level of improvement), knowledge management processes in business are constantly being improved. Automatic collection of both explicit (formalized) and implicit (unformalized) knowledge is provided. They are carefully analyzed and quantified to identify opportunities for further improvements to management processes. This level assumes the availability and use of appropriate tools. Such tools may include, for example, organizational structures, procedures and information technologies that provide audit, monitoring and examination of knowledge.

Based on the Maturity Models scale, which is based on determining the level of development of a business and IT system as a whole and its knowledge management system in particular from nonexistent (first level) to optimized (5th level), the auditor can determine:

- the current state of the business and its knowledge management system, that is, to assess what stage the business as a whole and its knowledge management system in particular are at the current time;

- the current status of best practice for knowledge management in the industry in which the business under study operates, that is, compare the specific business system and its knowledge management system being studied by the auditor with the best subject in the industry;

- the current status of the business and its knowledge management system in accordance with international best practices;

- the status of the business and its knowledge management system after their proposed improvement, that is, evaluate its business strategy for the results that it seeks to achieve in the field of knowledge management in the long term.

After identifying critical points and bottlenecks in the study area, Maturity Models allow the auditor to develop preliminary corrective recommendations and provide them with the management of the business under study. Then the auditor develops a strategy and tactics for bringing the business as a whole and its knowledge management system in particular to the desired level of knowledge management efficiency.

It should be especially noted that the nature of the relationship between the auditor and the managing and managed business systems depends on the conditions in which the audit of implicit (informal) knowledge is implemented regardless of its thematic focus (general audit of knowledge, assessment of corporate culture, collection and systematization of informal knowledge, interaction with business knowledge holders leaving this business, to identify their implicit (informal) knowledge, the existing innovative aspect, conducting on lying training or retraining of the staff of the business, the effectiveness of the use of social networks, etc.).

Therefore, even before the start of the audit, the essence of the audit engagement is necessary:

- inform interested business personnel about the objectives and terms of the audit study;

- to present to managers and knowledge holders the composition of the audit team and expert experts involved in carrying out the audit assignment;

- coordinate all the powers to access any, including confidential business information and its key knowledge carriers;

- agree on the duties and responsibilities of specific leading personnel of the business under study and key knowledge carriers; 


\section{ENTREPRENEURSHIP AND SUSTAINABILITY ISSUES}

ISSN 2345-0282 (online) http://jssidoi.org/jesi/

2020 Volume 7 Number 3 (March)

http://doi.org/10.9770/jesi.2020.7.3(56)

- discuss the knowledge audit methodology;

- answer all possible questions that have arisen from the staff of the studied business regarding the essential aspects of the upcoming audit study.

When planning an audit of the knowledge of a particular business, the auditor should take into account that almost all of its subject areas should be subject to audit research. However, practice shows that the timing and scale of the upcoming audit do not allow to fully cover the entire business under study. Therefore, to improve the quality and effectiveness of the audit cycle, it is necessary to pre-select the most significant aspects for the business, constantly supplementing and expanding the range of studies both in the audit process on the merits of the audit engagement and in subsequent audit studies.

It should be specially noted that the planning process must be carried out in three consecutive and interrelated stages: preliminary planning (identifying areas of knowledge carriers that are significant for business), strategic planning (developing a strategy for the upcoming audit) and ongoing planning (developing methods and preparing tools for conducting substantive audits audit assignment.

Despite the fact that each of these stages has its own characteristics and some resulting individuality, however, their practical implementation is due to close interdependence, since any adjustments in one of them will necessarily lead to changes in the others. Therefore, when planning audit of implicit (unformalized) knowledge, it is necessary to be guided by the generally recognized principles of continuity, complexity and optimality.

At the same time, continuity in this context should be understood as the installation of specific tasks interconnected at all stages of the audit of knowledge for a group of auditors and specialists- experts. In its turn, the complexity of planning an audit of knowledge refers to the interconnectedness and consistency of all the previously mentioned planning stages. And, finally, the principle of optimal planning for this audit consists in the choice by the auditor of the most important subject areas for the business being studied, which will allow to obtain the greatest effect from the results of the entire audit cycle.

Starting the stage of a detailed audit of the essence of the audit engagement, as noted earlier, to study implicit (non-formalized) knowledge, the auditor should consider the possibility of using heuristic methods based on the admissibility, rationality and even satisfactoriness of the prepared management recommendations. The specified system of methods will allow us to assess the quality indicators characterizing the effectiveness of the functioning of the knowledge management system, and as a result of management decisions.

It should be borne in mind that the use of heuristic methods to assess implicit (non-formalized) knowledge and the entire knowledge management system at a qualitative level when performing a knowledge audit is due to:

- the qualitative nature of implicit (non-formalized) knowledge;

- significant uncertainty of the probability of their formalization;

- the current lack of technologies that allow the construction and study of a formalized model of this knowledge. In this regard, the use by the auditor of expert assessment methods (questioning, interviewing, etc.) is noteworthy. However, these methods require a special approach to the formation of a group of specialists- experts with the proper competence in the subject areas being studied. Moreover, a group of specialists - experts can be both homogeneous and consist of specialists in various subject areas.

At the same time, it must be borne in mind that the practice of using these methods shows that their integrated application is most effective for solving the same problem. In addition, each of the methods, as noted earlier, involves some preparation for their implementation.

In addition to the specified qualitative methods aimed at identifying implicit (non-formalized) knowledge, a qualitative assessment of the knowledge management system and management decisions made on their basis, 


\section{ENTREPRENEURSHIP AND SUSTAINABILITY ISSUES}

ISSN 2345-0282 (online) http://jssidoi.org/jesi/

2020 Volume 7 Number 3 (March)

http://doi.org/10.9770/jesi.2020.7.3(56)

during the audit of knowledge on the merits of the audit task, the auditor needs to conduct a study of knowledge flows, that is, to identify the relationship of personnel, business and IT processes and technologies. These studies will reveal the insufficiency or duplication of this or that knowledge, as well as the best practices and existing barriers in the business system for using both explicit (formalized) and implicit (non-formalized) knowledge.

\section{Results}

It should be mentioned that these approaches, implemented in an audit of knowledge, allow us to identify the likely success factors of the business under study. For this, in the course of the audit study, it is necessary to focus not on a separate group of specialists of knowledge carriers, but to try to cover the staff of the entire business. In this case, the key aspect is precisely the assessment of factors that can serve either as barriers to the use of knowledge or to facilitate an effective exchange of knowledge.

Thus, it should be noted that a detailed audit of knowledge allows us to determine the patterns of knowledge flows in business that form ideas about the approaches used to process information and, as a result, the efficiency of the use and exchange of knowledge in this system.

Practice shows that according to the results of the knowledge audit it is advisable not only to prepare a report and management recommendations, but also to conduct knowledge mapping.

Knowledge Maps are not only an appropriate way of fixing and exchanging explicit (formalized) knowledge, but also a reflection of implicit (unformalized) knowledge with varying degrees of detail. These documents enable managers of the business under study to understand what knowledge is needed for a particular business staff. In addition, they allow you to separate explicit (formalized) knowledge, which is inherently accessible information, from implicit (unformalized), requiring a special approach to them from the knowledge management system.

According to I.V. Kozlova, and with which one cannot disagree, the goal of developing Knowledge Maps is the formation of special documents in the form of a separate new intellectual product, which is essentially a source of knowledge, as they reveal the links between sources of knowledge or indicate gaps in existing knowledge assets (Kozlova, 2016). At the same time, Knowledge Maps should not be identified with knowledge stores, where the entire body of business knowledge is directly stored. Knowledge cards are a kind of guide to the indicated repositories, specialists, knowledge carriers, sources of knowledge, etc. The process of creating Knowledge Maps is mainly focused on the definition and planning of the knowledge management system of any business (Kozlova, 2016).

When creating Knowledge Maps to describe the subject area, it is most expedient to use thesaurus modeling of knowledge. This approach allows you to effectively use thematic thesauruses, which forms the basis of a systematic idea of the content of the concepts of the subject area and its structure, the development of logical, associative and creative thinking, training of memory and imagination.

At the same time, the thesaurus (from Greek language - treasure, treasury) is understood as structured and organized knowledge containing the most complete amount of vocabulary on a certain topic with an indication of clearly expressed semantic relations between concepts (Andrusenko, 2007).

Among a significant number of Knowledge Maps used in practice, we may distinguish the most general types of knowledge applicable to any business system (table 1). 
ENTREPRENEURSHIP AND SUSTAINABILITY ISSUES

ISSN 2345-0282 (online) http://jssidoi.org/jesi/

2020 Volume 7 Number 3 (March)

http://doi.org/10.9770/jesi.2020.7.3(56)

Table 1. Knowledge Maps and their characteristics

\begin{tabular}{|l|l|}
\hline Types of Knowledge Maps & Characteristic \\
\hline Process Oriented Knowledge Maps & $\begin{array}{l}\text { Reflect knowledge and its sources supporting the main } \\
\text { business and IT processes of the business system. These maps } \\
\text { are mlformed according to the results of a study of business } \\
\text { operations and the external environment of the business. }\end{array}$ \\
\hline Conceptual Knowledge Maps & $\begin{array}{l}\text { Reflect the hierarchical classification in the form of concepts } \\
\text { and semantic relations between them. Used when comparing } \\
\text { similar business projects, turning knowledge into related and } \\
\text { explicit (Kozlova, 2016). }\end{array}$ \\
\hline Competency Maps & $\begin{array}{l}\text { Reflect the skills of one or another specialist, his advancement } \\
\text { on the hierarchical ladder and professionalism. Allow the } \\
\text { management system to search for experts in various subject } \\
\text { areas within the business system }\end{array}$ \\
\hline Social Net Maps & $\begin{array}{l}\text { Reflect knowledge graph and communication models of } \\
\text { business systems among various groups of practitioners, } \\
\text { business partners and other social environments. Allow to } \\
\text { analyze ways of sharing knowledge in the process of } \\
\text { collaboration. }\end{array}$ \\
\hline Strategic Knowledge Maps & $\begin{array}{l}\text { Reflect the share of business initiative in the development of a } \\
\text { product, product or service }\end{array}$ \\
\hline Advanced Development Distribution Maps & $\begin{array}{l}\text { Show the experience and data of the use of various business } \\
\text { processes by the business system. Directs a business system } \\
\text { specialist who is interested in advanced developments in a } \\
\text { specific subject area to business resources and groups that } \\
\text { actively use advanced ideas }\end{array}$ \\
\hline
\end{tabular}

Source: own research

\section{Discussion}

As it was mentioned earlier, a report based on the results of a knowledge audit, as well as generated Knowledge Maps, are not a stage in completing the entire cycle of a specified audit. Research and practice of the implementation of the audit of knowledge shows that the greatest effect of the implementation of management recommendations developed on the basis of the audit is possible only with continuous monitoring of the process of their implementation and use. This approach allows you to timely carry out the necessary additional research and adjustments to management decisions made on the basis of audit recommendations.

\section{Conclusions}

Thus, it should be admitted that the knowledge audit cycle does not end with the stage of preparation and presentation of the audit report, but continues throughout the support of management decisions based on its results. An audit of knowledge accompanies these decisions until they are fully implemented, that is, until the final effect is obtained. Knowledge audit, similar to other types and methods of audit, aims to assess the current state of the business, but the main attention here is aimed at determining the availability of knowledge, further needs for them, establishing knowledge flows and their use in business processes to add value to the organization. Knowledge audit is an important tool for assessing the readiness of a business to implement a knowledge management system and further monitor its functioning. 


\section{ENTREPRENEURSHIP AND SUSTAINABILITY ISSUES}

ISSN 2345-0282 (online) http://jssidoi.org/jesi/

2020 Volume 7 Number 3 (March)

http://doi.org/10.9770/jesi.2020.7.3(56)

\section{References}

Akhmadeev, R.G., Bykanova, O.A., Salomadina, P.S. (2019). The effect of the VAT change on the final consumer. Proceedings of the 33rd International Business Information Management Association Conference, IBIMA 2019: Education Excellence and Innovation Management through Vision 2020, 765-770.

Akhmetshin, E. M., Plaskova, N. S., Iusupova, I. I., Prodanova, N. A., Leontyev, A. N., \& Vasilev, V. L. (2019). Dataset for determining rational taxation value with incompatible criteria of economic efficiency and equity. Data in Brief, 26 https://doi.org/10.1016/j.dib.2019.104532

Andrusenko T.B. (2007). Methods of knowledge audit. Corporate systems, 1. http://www.management.com.ua/ims/ims129.html

Gardner J.W. (1981). Self-Renewal: The Individual ends Innovatic Society. Rev. ed. NY: W.W. Norton. 118 p.

Golubkov E. P. (2005) Technology of managerial decision-making. Moscow: Publishing house "Business and Service", 544 p.

Gibbert M., Leibold M., \& Probst G. (2002). Five styles of customer knowledge management, and how smart companies use them to create value. European Management Journal, 20(5), 459-469.

Hilkevics, S., Semakina, V. (2019). The classification and comparison of business ratios analysis methods. Insights into Regional Development, 1(1), 48-57. https://doi.org/10.9770/ird.2019.1.1(4)

Vyatkina E. O., \& Sitnov A.A. (2018). Unformalized Knowledge Audit as a Modern Management Tool. Proceeding ICETM 2018 Proceedings of the 2018 International Conference on Education Technology Management, 3-6.

Ibbs C. W., \& Kwak Y.-H. (1997). The Benefits of Project Management: Financial and Organizational Rewards to Corporations. Newtown Square, Pennsylvania, USA: Project Management Institute, 1997.

Kashirskaya, L., Sitnov, A., \& Abbasova, S. (2019). Audit as a key tool for business knowledge management system research. 37th International Scientific Conference on Economic and Social Development - Socio Economic Problems of Sustainable Development - Baku, 14-15 February 2019, pp. 459-468.

Kozlova, I.V. (2016). Structural analysis of documentary subject of information resources. International Research Journal, 1-2(43), 38-40. https://doi.org/10.18454/IRJ.2016.43.002

Korableva, O. N., Kalimullina, O. V., \& Mityakova, V. N. (2018). Innovation activity data processing and aggregation based on ontological modelling. Paper presented at the 2018 4th International Conference on Information Management, ICIM 2018, 1-4. https://doi.org/10.1109/INFOMAN.2018.8392659

Kotyrlo, E. S. (2011). Human potential and human capital as scientific categories. Audit and financial analysis, 6, 1-7.

Koulopoulos, T.M., Frappaolo, C. (1999). Smart things to know about Knowledge Management. Capstone Publishing Limited, Oxford Centre for Innovation, Oxford OX2 0JX, United Kindom.

Korchevenkov, S., Aleksandrova, T. (2018). Investigation of the influence a morphologic characteristics of the noble metal particles on gravity efficiency devices. Paper presented at the International Multidisciplinary Scientific GeoConference Surveying Geology and Mining Ecology Management, SGEM, 18(1.4), 99-104. https://doi.org/10.5593/sgem2018/1.4/S04.013

Kopteva, A., Koptev, V., Malarev, V., \& Ushkova, T. (2019). Development of a system for automated control of oil transportation in the arctic region to prevent the formation of paraffin deposits in pipelines. Paper presented at the E3S Web of Conferences, 140 https://doi.org/10.1051/e3sconf/201914007004

Lafer, S., \& Tarman, B. (2019). Editorial 2019: (2)1, Special Issue. Journal of Culture and Values in Education, 2(1), i-v. Retrieved from http://cultureandvalues.org/index.php/JCV/article/view/34

Luzina, T. V., Dudareva, E. A., Akhmetshin, E. M., Prodanova, N. A., Berdova, Y. S., \& Emaletdinova, G. E. (2019). International legal format for trans regionalisation of trade and economic partnership within BRICS in global development. Space and Culture, India, 7(3), 76-85. https://doi.org/ 0.20896/saci.v7i3.508 


\section{ENTREPRENEURSHIP AND SUSTAINABILITY ISSUES}

ISSN 2345-0282 (online) http://jssidoi.org/jesi/

2020 Volume 7 Number 3 (March)

http://doi.org/10.9770/jesi.2020.7.3(56)

Magsumov, T.A. (2017). Family and school in Russia at the beginning of the 20th century: Attempts to bridge the gap. European Journal of Contemporary Education, 6 (4), 837-846. https://doi.org/10.13187/ejced.2017.4.837

Makarov, A. M. (2005). Results of research of intellectual capital of industrial enterprises of the Udmurt Republic. Materials of the seventh scientific-practical conference of teachers and the staff of the Udmurt state University, Izhevsk.

Meskon, M. H., Alber, M., Hedouri, F. (2002). Fundamentals of management: Per. with English. M.: Business, 704 p.

Nagimzhanova, K. M., Baimanova, L., Magavin, S. S., Adzhibaeva, B. Z., \& Betkenova, M. S. (2019). Basis of psychological and professional personality development of future educational psychologists. Periodico Tche Quimica, 16(33), 351-368.

Nayanova, K. (2001). Work in smart style. Kompyuterra, No. 191. http://www.ibusiness.ru/offl ine/2001/191/14768/print.html

Nigamaev, A. Z., Gapsalamov, A. R., Akhmetshin, E. M., Pavlyuk, A. V., Prodanova, N. A., \& Savchenkova, D. V. (2018). Transformation of the tax system during the middle ages: The case of Russia. European Research Studies Journal, 21(3), $242-253$.

Neizvestnaya, D.V., Kozlova, N.N., \& Prodanova, N.A. (2018). Application of CVP-Analysis at the Water Transport Organizations. Helix, 8(1), 2811-2815. https://doi.org/10.29042/2018-2811-2815

Nonaka I., \& Takeuchi, H. (1995). The Knowledge-Creating Company: How Japanese Companies Create the Dynamics of Innovation. Oxford University Press, New York.

Novgorodov, P.A. (2017). Intellectual capital: concept, essence, structure. Bulletin of Udmurt University. Ser. Economy and law. V. 27(2), 38-49.

Prakash, R., \& Garg, P. (2019). Comparative assessment of HDI with Composite Development Index (CDI). Insights into Regional Development, 1(1), 58-76. https://doi.org/10.9770/ird.2019.1.1(5)

Prodanova, N., Plaskova, N., Popova, L., Maslova, I., Dmitrieva, I., Sitnikova, V., \& Kharakoz, J. (2019). The role of IT tools when introducing integrated reporting in corporate communication. Journal of Advanced Research in Dynamical and Control Systems, 11(8 Special Issue), 411-415.

Saenko, N., Voronkova, O., Volk, M., \& Voroshilova, O. (2019). The social responsibility of a scientist: Philosophical aspect of contemporary discussions. Journal of Social Studies Education Research, 10(3), 332-345.

Sharafutdinov, R., Gerasimov, V., Akhmetshin, E., Karasik, E., \& Kalimullina, O. (2019). Inclusive development index in Russia: analysis, methods, possibility of application. Revista Genero \& Direito, 8(4), Special Issue, 231-241.

Simon, H. A. (1995). Management in organizations. M.: Economy, 335 p.

Sitnov, A.A., \& Urintsov A.I. (2014). Audit of information systems: monograph for masters. M.: UNITY-DANA

Smolnikova, F., Tokhtarov, Z., Kenijz, N., Nelyubina, E., Grigoryants, I., Bobkova, E., ... Nikolaeva, N. (2019). Technological process of germination of wheat grain under the water tincture of aloe and its physical-chemical properties. International Journal of Innovative Technology and Exploring Engineering, 9(1), 184-187. https://doi.org/10.35940/ijitee.A3974.119119

Stewart, T. A. (2001). Intellectual capital: the hidden gold. Highlights of the opening address by Thomas A. Stewart at The Learning. URL: http://leadership.gc.ca/static/dayinthelife/learning/features/summit/stewart_thomas_e.shtml

Sveiby, K.E. (2004). Methods for Measuring Intangible Assets Jan 2001, updated April 2001, May 2002, October 2002 , April 2004. Available source: http://www.sveiby.com/articles/Measure Intangible Asets.html

Suryono, S., Surarso, B., Saputra, R., \& Sudalma, S. (2019). Real-time decision support system for carbon monoxide threat warning using online expert system. Journal of Applied Engineering Science, 17(1), 18-25.

Thalassinos, I.E., Thalassinos, Y. (2018). Financial Crises and e-Commerce: How Are They Related.

Available at SSRN: https://ssrn.com/abstract=3330169. 


\title{
ENTREPRENEURSHIP AND SUSTAINABILITY ISSUES
}

ISSN 2345-0282 (online) http://jssidoi.org/jesi/

2020 Volume 7 Number 3 (March)

http://doi.org/10.9770/jesi.2020.7.3(56)

Trofimova, L., Prodanova, N., Korshunova, L., Savina, N., Ulianova, N., Karpova, T., \& Shilova, L. (2019). Public sector entities' reporting and accounting information system. Journal of Advanced Research in Dynamical and Control Systems, 11(8 Special Issue), 416424.

Voronkova, O. Y., Perepechkina, E. G., Shichiyakh, R. A., Kuts, V. I., Sungurov, P. A., \& Glazkova, G. V. (2019). Ecological and economic potential and prospects for organic production in the regions of Russia. International Journal of Economics and Business Administration, 7, 583-594.

Yemelyanov, V., Yemelyanova, N., \& Nedelkin, A. (2018). Diagnostic system to determine lining condition. Paper presented at the MATEC Web of Conferences, 172 https://doi.org/10.1051/matecconf/201817204001

\section{Liudmila KASHIRSKAYA}

Professor, Doctor of the Economic Sciences, Financial University under the Government of the Russian Federation, Russia. Research interests - accounting expertise, state financial control, audit, departmental interaction, efficiency of activity.

ORCID ID: https://orcid.org/0000-0002-0234-0223

\author{
Alexey SITNOV \\ Professor, Doctor of the Economic Sciences, Financial University under the Government of the Russian Federation, Russia. \\ ORCID ID: https://orcid.org/0000-0003-2221-4037
}

\section{Dilmurod DAVLATZODA}

Candidate of Economic Sciences, Associate Professor, Russian-Tajik (Slavonic) University (RTSU), Tajikistan.

ORCID ID: https://orcid.org/0000-0003-0115-7731

\section{Tatiana VOROZHEYKINA}

Doctor of Economics, Associated Professor, Department of Production Organization, Russian State Agrarian University - Moscow Agricultural Academy named after K.A. Timiryazev, Russia.

ORCID ID: http://orcid.org/0000-0001-7295-1372

Register for an ORCID ID:

https://orcid.org/register

Copyright (C) 2020 by author(s) and VsI Entrepreneurship and Sustainability Center

This work is licensed under the Creative Commons Attribution International License (CC BY).

http://creativecommons.org/licenses/by/4.0/

(c) (i) Open Access 